\title{
POTENTIAL OF PERSONAL RAPID TRANSIT SYSTEM TO MEET THE URBAN TRANSPORT DEFICIT
}

\author{
Udit Jain ${ }^{1}$, Pradip Sarkar ${ }^{2}$, Anupam Vibhuti ${ }^{3}$ \\ ${ }^{1}$ Civil Engineering Department, Indian Institute of Technology Roorkee, Uttarakhand, India \\ ${ }^{2}$ School of Planning and Architecture, New Delhi, India \\ ${ }^{3}$ Worxpace CPL, East of Kailash, New Delhi, India
}

Received 2 March 2016; accepted 5 August 2016

\begin{abstract}
There is a rapid increase in the use of personal modes of transport over public transport. In spite of tremendous efforts to promote public transport by the authorities; the personal mode users still prefer their own vehicles for transportation. The personal mode users resist the public transport for various reasons like comfort, waiting time, sense of privacy and access-egress trips. This study focuses on the access-egress trips and how Personal Rapid Transit (PRT) can be used to meet this deficit in the urban transportation system. PRT is an efficient rapid transit system which provides the last mile connectivity to the users with high level of reliability and comfort. It is a demand responsive system that ensures uninterrupted point to point journey between origin and destination. Dwarka, New Delhi, in India has been taken as the case study area to study how a PRT system effects the accessibility of public transport in an area. Primary and secondary data has been collected to understand the characteristics of the existing mass rapid transit system (Delhi Metro) and city bus services (DTC) in Dwarka. A PRT network of $18 \mathrm{~km}$ has been proposed in Dwarka which forms loops around the existing MRTS line and passes through the neighboring residential, commercial and institutional areas. Further, the impact of introducing this network on the accessibility levels in the area have been studied. The Public Transport Accessibility Level (PTAL) methodology developed by the London Borough of Hammersmith and Fulham has been adopted for calculation of Accessibility Index.
\end{abstract}

Keywords: Personal Rapid Transit (PRT), Accessibility Index, Public Transport Accessibility Level (PTAL), Dwarka.

\section{Introduction}

Personal rapid transit (PRT) vehicles are small fully automated vehicles (pod-cars) that carry individuals or a small group of 2 to 6 people. As the name suggests, the idea is to provide the user with highest level of comfort as a personal car would. PRT runs on dedicated guideways which may form linear routes or a network of loops (Vibhuti,
2009). It works most efficiently in a network of small loops which have frequent merging and diverging points (Anderson, 1978). The stations are constructed with a by-passable separate track which ensures a non-stop point to point journey between the origin and destination of the user (Anderson, 2009). It is a highly flexible and light weight system which incurs a low capital cost. (European Commission, 2004; Gilbert and Anthony,

${ }^{1}$ Corresponding author: uj143.dce2014@iitr.ac.in 
2006). PRT has also been chosen as one of the modes of transportation in the world's first zero emission sustainable city project of Masdar City in United Arab Emirates (De Graff, 2011). Several researchers have recommended ways to reduce the share of private vehicle trips in cities (Moeinaddini et al., 2012; Kumar et al., 2013). PRT is also one of the potential solutions to this problem.

The concept of PRT was conceived in 1953 by Don Fichter who conducted a research on alternative transportation methods (Anderson, 1996). An operational PRT system was first introduced in 1975 in West Virginia University in Morgantown, USA (Anderson, 1996). PRT got real momentum only after 2011 when PRT operations began at Heathrow Airport Terminal 5 (Sarkar et al., 2012). Since then the world has realized the potentials of PRT system and it is now being considered for public transport planning studies in various cities around the world. The Morgantown PRT connects the three campuses of West Virginia University in Morgantown, USA. It is also known as Automated Group Rapid Transit system. There is some disagreement whether Morgantown system is a true PRT system or not because it has a capacity to hold 21 person ( 8 seated \& rest standing), which is a high number when compared to most PRT concepts (Anderson, 1996). The total length of this system is $13.2 \mathrm{~km}$.

As of February 2016, three modern PRT systems are operational worldwide - Masdar PRT, Heathrow PRT and Suncheon PRT (Gustafsson et al., 2013; ATA, 2016). The Masdar PRT was introduced in November 2010 in Masdar city, Abu Dhabi. It is a mere $1.4 \mathrm{~km}$ long PRT providing a link to the Masdar Institute of Science and Technology (De Graff, 2011). The Heathrow PRT was opened in 2011 at the Heathrow airport in London, UK. It is a $3.8 \mathrm{~km}$ long PRT route with 21 vehicles connecting Terminal 5 of the airport to the business car park. The third PRT system was opened in August 2013 in Suncheon, South Korea. It is a 4.6 $\mathrm{km}$ network operating at a maximum speed of $60 \mathrm{kmph}$ in the Suncheon coastal wetlands (Gustafsson et al., 2013). Additional PRT systems have also been announced at Heathrow Airport in UK and Amritsar city in India (Ultra Fairwood, 2009; Ultra Global, 2013; Ultra Global, 2014). Several PRT systems have been proposed which are substantially larger than the ones operational today. The implementation of these proposed systems is yet to be seen (Ultra Fairwood, 2009; Muller, 2009).

One of the lesser highlighted benefits of PRT is the level of accessibility it provides to an area. The society may be classified into two groups when it comes to choosing a mode of transportation. First is the 'Time Savers Society' and the second is the 'Money Savers Society'. In developing countries, the percentage of the latter is larger and thus the modal share is in the favor of public transport. The 'Money Savers Society' is usually comprises of captive riders to a public transportation system whereas the 'Time Savers Society' comprises of choice riders. Over the years as the world economies have grown, the purchasing power of the users has also increased. There has been a shift in the society from 'Money Savers' to 'Time Savers' and the exponential growth of private modes of transport has been observed. The impact of increase in the vehicular emissions has been felt globally. The authorities all over the globe are taking initiatives to promote Public Transport but they often fail to attract the 'Time Saver' section of the society. The 'Time Savers Society' gives priority to time 
and comfort and avoids public transport systems because of the unavoidable halts at every station and the tussle for space in the buses and rail transit coaches. The conventional modes of public transport are not designed for last mile connectivity and seamless travel. The access and egress time associated with a public transport modes plays a very important role in mode choice behavior of users. PRT integrates the benefits of personal vehicles and public transport to some extent and has the potential to attract the 'Time Savers Society' and other users to public transport. A properly designed PRT network can tackle the issues of last mile connectivity and acceptable walking distances associated with public transport and enhance the accessibility of public transport in an area (European Commission, 2004).

In India, the largest operating MRTS network is Delhi Metro. It has been observed that accessibility of the Delhi Metro has been one of the reasons why people tend to prefer personal vehicles over MRTS. The existing access modes include cycle rickshaws and personal vehicles. The former is a labor and time intensive mode with no fixed fare guidelines and the latter faces the problem of insufficient parking facilities at the MRTS stations. Fifteen sectors of Dwarka in New Delhi, India have been selected as the case study area to study how introducing a PRT system would impact the Public Transport Accessibility Levels (PTALs) of an area. Several techniques have been used by researchers to assess the accessibility levels in urban areas (Šimecki et al., 2013; Balya et al., 2016). The PTAL methodology developed Transport for London in 2010 is one such technique. In this study, the existing PTALs (Without PRT) and the new PTALs (After PRT) have been compared to study how the accessibility improves after introducing a PRT system.

\section{Case Study - Dwarka, New Delhi, India}

Dwarka Sub City is situated in South West Delhi part of National Capital Territory of Delhi and is the zone K-II in the zoning system given by the Delhi Development Authority. Dwarka has a location advantage as it is very close to Gurgaon which is one of the largest business hubs in the National Capital Region. Dwarka is also adjacent to Indira Gandhi International Airport, New Delhi. Dwarka was divided into 29 sectors when it was planned by the Delhi Development Authority (DDA). It has a total population of 11 Lakhs (1.1 Million) in these 29 sectors. The total area of the sub city is 5924 hectares and the existing built up area is 1933 hectares. Dwarka is one of the largest planned residential areas in Asia. It is also known as the "Model Township" and is considered to be one of the most organized and cleanest areas of Delhi. As compared to other colonies and townships in Delhi, Dwarka has wide roads and a well-developed road network. Dwarka is well connected to various other areas of Delhi by the city bus routes and Delhi Metro Blue Line. The majority of residents of Dwarka belong to the Middle Income group (MIG) and High Income Group (HIG) category. There are well established and authorized commercial areas which attract recreational and shopping trips. There are large universities campuses like Guru Gobind Singh Indraprastha University and Netaji Subhash Institute of Technology which attract education and work trips every day.

PRT has been planned in the case study area to cater to the "Intra Dwarka Trips" which 
are the trips contained within Dwarka sub city. Intra Dwarka Trips consist of access dispersal trips to the bus stops and metro stations, shopping trips, recreational trips and educational trips within Dwarka.

\section{Travel Demand Estimation \& Proposed PRT Route}

Primary and secondary data has been collected for the demand assessment of Intra Dwarka trips and development of a PRT system in Dwarka. The secondary data has been collected from various sources like Delhi Development Authority (DDA), and Fairwood Group Pvt. Ltd. The primary data has been collected through different surveys conducted in Sector - 3, 4, 5, 6, 7, 8, 9, 10, 11, $12,13,14,16,21$, and 22 (Total 15 sectors) of Dwarka. The study area sectors selected in Dwarka have been shown in Fig. 1a.

Household socio economic and trip information has been collected from the residential areas and the similar information has been collected from the commercial and institutional areas in the establishment survey. Willingness to shift (WTS) and willingness to pay (WTP) surveys have been conducted using stated preference technique during both household and establishment surveys. These surveys are user opinion surveys where the users are first informed about Personal rapid System, its utilities and benefits. Then the users are asked if they will be willing to shift to PRT if it is introduces in their area. If the answer is yes then they are asked at what fare they will be willing to shift to the PRT system. The Base Year Intra Dwarka Trips in the study area are 607,496 Trips per Day. Binary Logit Model has been used to calculate the percentage shift to PRT from each of the existing mode in Dwarka. Out of the total 607,496 Trips per day, there is $36.6 \%$ overall shift expected to PRT at the base fare of INR $10 / \mathrm{km}$. The Estimated Travel Demand for PRT in Dwarka is 222,465 Trips/Day. The detailed analysis travel demand assessment of PRT in Dwarka has been reported by Jain et al. (2016).

A PRT route network of $18 \mathrm{~km}$ length has been proposed in the case study area to meet the estimated travel demand. The network has been designed as a feeder to the existing MRTS line to provide the last mile connectivity to the users. While designing the PRT network the maximum walking distance has been taken as 200 meters to access a PRT station from any of the sectors. The network has been made in small loops running parallel to the Blue Line of Delhi Metro. The network connects all the major metro stations, residential areas, commercial areas and the institutional areas in the study area. The proposed route network has been shown in Fig. $1 b$. 


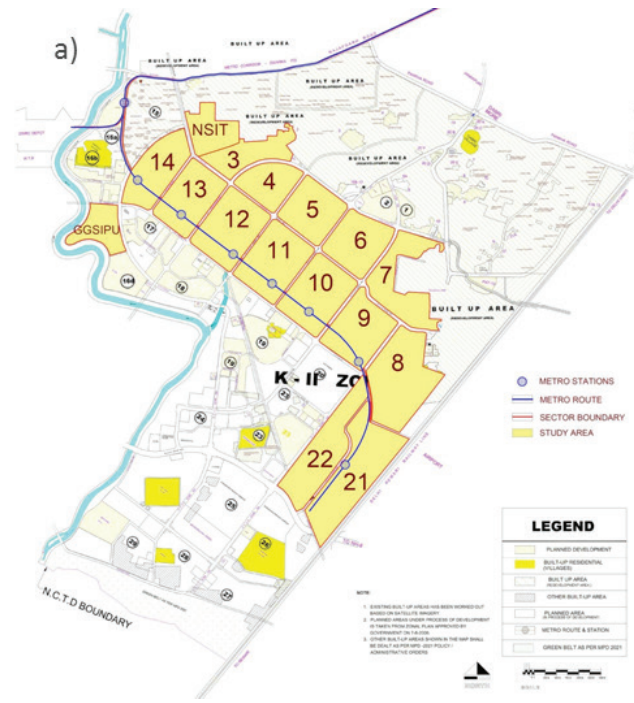

Fig. 1.

a) Study Area - Dwarka, New Delhi, India

b) Proposed PRT Route in Dwarka

\section{Concept of Public Transport Accessibility Levels (PTALs)}

The methodology of PTALs was developed by the London Borough of Hammersmith and Fulham. It was later adopted by Transport for London as the standard method for calculation of public transport access in London (London Datastore, 2014). PTALs are a detailed and accurate way to measure of the accessibility of an area to the public transport network. It takes into account walk access time and service availability. This method is essentially measures the density of the public transport network at any location in a given area. Using PTALs accessibility is measured based on both the access distance to public transport services and the level of service provided to the user (Transport for London, 2010). Following are the steps involved in calculating the Accessibility Index and the PTALs:

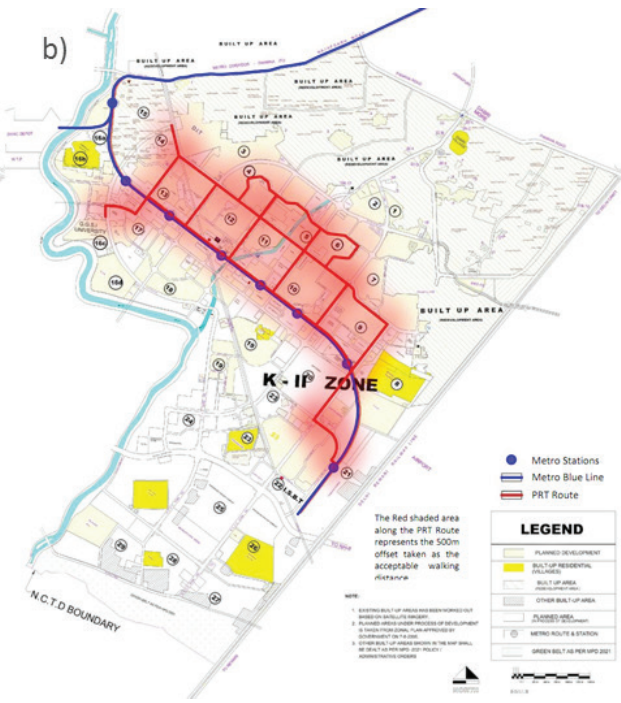

Step 1:

First step is to identify all the Public Transport services available in the area. Identify all the routes of each of the Public Transport modes and the scheduled frequency of each of the route in the peak hour.

\section{Step 2:}

Identify the Point of Interest (POI) and the Service Access Points (SAP). POI is the origin point from where the user starts the trip to the SAP to access the Public Transport System. The SAP is the destination point from where the user will get into the Public Transport System. The SAP can be a bus stop, metro rail station or a PRT station.

\section{Step 3:}

The Total Access Time is calculated. It is the time taken to access the Public Transport System from the POI to the nearest SAP. The 
Total Access Time is calculated separately for each of the available Public Transport mode. The Total Access Time is the sum of Time taken to reach the SAP from the POI and the Waiting Time at the SAP.

Access Time $=$ Travel time between the POI and SAP by walk or cycle rickshaw.

Waiting Time $=0.5 \times(60 \div$ Scheduled Frequency)

Total Access Time $=$ Access Time between POI \& SAP + Waiting time for next Service

\section{Step 4:}

Once the Total Access Time is calculated, calculate the Equivalent Doorstep Frequency (EDF). This treats Total Access Time as a notional average waiting time as though the route was available at the doorstep of the selected POI. The following formula is used to calculate the EDF:

Equivalent Doorstep Frequency $(\mathrm{EDF})=$ $30 \div$ Total Access Time
EDF for the POI are calculated for each mode separately, i.e., $\mathrm{EDF}_{\text {Mode1 }}$ of Bus at the POI, then $\mathrm{EDF}_{\text {Mode2 }}$ of Metro Rail at the same POI and so on for all the available Public transport modes.

\section{Step 5:}

After calculating the EDF of all the modes at the POI, the Accessibility Index for the POI is calculated. Accessibility Index (AI) is the sum of all the EDF of different modes at the POI.

Accessibility Index $(\mathrm{AI})=\mathrm{EDF}_{\text {Model }}+$ $\mathrm{EDF}_{\text {Mode2 }}+\ldots \ldots+\mathrm{EDF}_{\text {Moden }}$

\section{Step 6:}

Public Transport Accessibility Index (PTAL) of the POI is calculated after calculating the Accessibility Index of the POI. PTAL is a band of 6 colours from 1 to 6 , where 1 indicates very poor accessibility and 6 indicates excellent level of accessibility. It is derived from the Range of Accessibility Index of the POI. The colour coded PTAL bands are presented in Table 1.

Table 1

PTAL Bands Description

\begin{tabular}{|l|l|l|l|}
\hline PTAL & Range of Index & Description & Colour Band \\
\hline $1 \mathrm{a}($ Low $)$ & $0.01-2.50$ & Very Poor & \\
\hline $1 \mathrm{~b}$ & $2.51-5.00$ & Very Poor & \\
\hline 2 & $5.01-10.00$ & Poor & \\
\hline 3 & $10.01-15.00$ & Moderate & \\
\hline 4 & $15.01-20.00$ & Good & \\
\hline 5 & $20.01-25.00$ & Very Good & \\
\hline $6 \mathrm{a}$ & $25.01-40.00$ & Excellent & \\
\hline $6 \mathrm{~b}$ (High) & $40.01+$ & Excellent & \\
\hline
\end{tabular}

Source: Greater London Authority, London Datastore (2014) 
5. Existing Public Transport Accessibility Level of the Study Area

Existing modes of Public Transport in Dwarka are the Delhi Transport Corporation (DTC) Buses and Delhi Metro Rail. At present when there is no PRT system in Dwarka, and people use cycle rickshaw, personal vehicle or walk to access and disperse from the metro stations. Fifteen Points of Interest (POI) have been selected in the Case Study Area and the existing accessibility index and PTAL have been calculated to see the current levels of accessibility of the fifteen sectors in Dwarka.

\subsection{DTC Buses Equivalent Doorstep Frequency (EDF)}

At each of the POI, the nearest Bus Stop (SAP) has been identified. The scheduled frequency of all bus routes at the SAP has been taken. The waiting time has been calculated using the formula mentioned in Step 3 and presented in Table 2.

Table 2

Waiting Time at the Bus Stops

\begin{tabular}{|l|l|l|l|l|}
\hline Location $(\mathbf{P O I})$ & $\begin{array}{l}\text { Nearest Bus Stop } \\
(\text { SAP })\end{array}$ & $\begin{array}{l}\text { Distance to Bus Stop } \\
(\mathbf{K m})\end{array}$ & $\begin{array}{l}\text { Scheduled Frequency } \\
(\text { Per Hour })\end{array}$ & $\begin{array}{l}\text { Waiting Time at Bus } \\
\text { Stop (Min) }\end{array}$ \\
\hline NSIT & SurajVihar & 0.60 & 28 & 1.1 \\
\hline GGSIPU & SampadaBhawan & 0.80 & 3 & 10.0 \\
\hline Sector 3 & MRV School & 0.30 & 32 & 0.9 \\
\hline Sector 4 & Matiyala Crossing & 0.60 & 22 & 1.4 \\
\hline Sector 5 & Sector 5 & 0.80 & 8 & 3.8 \\
\hline Sector 6 & Sector 6 Tele-Ex & 0.80 & 16 & 1.9 \\
\hline Sector 7 & Princess Park Sec 7 & 0.80 & 10 & 3.0 \\
\hline Sector 8 & Sector 9 & 0.75 & 8 & 3.8 \\
\hline Sector 9 & Royal Residency & 0.60 & 6 & 5.0 \\
\hline Sector 10 & Sec 10 Crossing & 0.75 & 12 & 2.5 \\
\hline Sector 11 & AshirwadChowk & 0.80 & 10 & 3.0 \\
\hline Sector 12 & AshokaApts & 0.50 & 10 & 3.0 \\
\hline Sector 13 & MRV School & 0.50 & 32 & 0.9 \\
\hline Sector 14 & Sector 13 & 0.80 & 32 & 0.9 \\
\hline Sector 21 & Sector 21 & 0.50 & 10 & 3.0 \\
\hline Sector 22 & Sector 21 & 0.80 & 10 & 3.0 \\
\hline & & & \\
\hline
\end{tabular}

The distance and access time to nearest bus stop (SAP) from the POI has been calculated. The walk speed considered for calculating Access Time has been taken as $1.2 \mathrm{~m} / \mathrm{s}$. Then the Total Access Time has been calculated by adding the Access Time and the Waiting Time. EDF is then calculated as $30 \div$ Total Access Time and presented in Table 3. 
Table 3

EDF of Bus

\begin{tabular}{|l|l|l|l|l|l|}
\hline Location $(\mathbf{P O I})$ & $\begin{array}{l}\text { Distance to Bus } \\
\text { Stop }(\mathbf{S A P}) \mathbf{K m})\end{array}$ & $\begin{array}{l}\text { Access Time to } \\
\text { Bus Stop }(\mathbf{M i n})\end{array}$ & $\begin{array}{l}\text { Waiting Time at } \\
\text { Bus Stop }(\mathbf{M i n})\end{array}$ & $\begin{array}{l}\text { Total Access } \\
\text { Time }(\mathbf{M i n})\end{array}$ & EDF $_{\text {bus }}$ \\
\hline NSIT & 0.60 & 8.3 & 1.1 & 9.4 & 3.19 \\
\hline GGSIPU & 0.80 & 11.1 & 10.0 & 21.1 & 1.42 \\
\hline Sector 3 & 0.30 & 4.2 & 0.9 & 5.1 & 5.88 \\
\hline Sector 4 & 0.60 & 8.3 & 1.4 & 9.7 & 3.09 \\
\hline Sector 5 & 0.80 & 11.1 & 3.8 & 14.9 & 2.02 \\
\hline Sector 6 & 0.80 & 11.1 & 1.9 & 13.0 & 2.31 \\
\hline Sector 7 & 0.80 & 11.1 & 3.0 & 14.1 & 2.13 \\
\hline Sector 8 & 0.75 & 10.4 & 3.8 & 14.2 & 2.12 \\
\hline Sector 9 & 0.60 & 8.3 & 5.0 & 13.3 & 2.25 \\
\hline Sector 10 & 0.75 & 10.4 & 2.5 & 12.9 & 2.32 \\
\hline Sector 11 & 0.80 & 11.1 & 3.0 & 14.1 & 2.13 \\
\hline Sector 12 & 0.50 & 6.9 & 3.0 & 9.9 & 3.02 \\
\hline Sector 13 & 0.50 & 6.9 & 0.9 & 7.9 & 3.81 \\
\hline Sector 14 & 0.80 & 11.1 & 0.9 & 12.0 & 2.49 \\
\hline Sector 21 & 0.50 & 6.9 & 3.0 & 9.9 & 3.02 \\
\hline Sector 22 & 0.80 & 11.1 & 3.0 & 14.1 & 2.13 \\
\hline
\end{tabular}

\subsection{Delhi Metro Rail Equivalent Doorstep Frequency (EDF)}

At each of the POI, the nearest Metro Rail Station (SAP) has been identified. The distance from POI to the nearest MRTS Node (SAP) has been taken to calculate the Access Time. Majority of metro rail users in Dwarka use cycle rickshaw as the access dispersal mode. The speed of cycle rickshaw has been taken as $15 \mathrm{kmph}$ to calculate the access time to nearest MRTS node. Delhi Metro in Dwarka runs at a 3 minutes headway in the peak hour which means the scheduled frequency is 20 services per hour.

Waiting Time $=0.5 \times(60 \div$ Scheduled Frequency)

$$
\begin{aligned}
& =0.5 \mathrm{X}(60 \div 20) \\
& =1.5 \mathrm{~min}
\end{aligned}
$$

Then the Total Access Time has been calculated by adding the Access Time and the Waiting Time. EDF is then calculated as $30 \div$ Total Access Time and presented in Table 4. 
Table 4

EDF of Metro Rail

\begin{tabular}{|l|l|l|l|l|l|}
\hline Location (POI) & $\begin{array}{l}\text { Distance to Nearest } \\
\text { MRTS Node (SAP) } \\
(\mathbf{K m})\end{array}$ & $\begin{array}{l}\text { Access Time To } \\
\text { Nearest MRTS } \\
\text { Node (Min) }\end{array}$ & $\begin{array}{l}\text { Waiting Time at } \\
\text { Platform (Min) }\end{array}$ & $\begin{array}{l}\text { Total Access } \\
\text { Time (Min) }\end{array}$ & EDF $_{\text {Metro }}$ \\
\hline NSIT & 2.00 & 8.0 & 1.5 & 9.5 & 3.16 \\
\hline GGSIPU & 1.75 & 7.0 & 1.5 & 8.5 & 3.53 \\
\hline Sector 3 & 2.50 & 10.0 & 1.5 & 11.5 & 2.61 \\
\hline Sector 4 & 2.50 & 10.0 & 1.5 & 11.5 & 2.61 \\
\hline Sector 5 & 2.75 & 11.0 & 1.5 & 12.5 & 2.40 \\
\hline Sector 6 & 3.00 & 12.0 & 1.5 & 13.5 & 2.22 \\
\hline Sector 7 & 2.00 & 8.0 & 1.5 & 9.5 & 3.16 \\
\hline Sector 8 & 1.25 & 5.0 & 1.5 & 6.5 & 4.62 \\
\hline Sector 9 & 1.50 & 6.0 & 1.5 & 7.5 & 4.00 \\
\hline Sector 10 & 0.75 & 3.0 & 1.5 & 4.5 & 6.67 \\
\hline Sector 11 & 1.00 & 4.0 & 1.5 & 5.5 & 5.45 \\
\hline Sector 12 & 1.00 & 4.0 & 1.5 & 5.5 & 5.45 \\
\hline Sector 13 & 1.00 & 4.0 & 1.5 & 5.5 & 5.45 \\
\hline Sector 14 & 1.00 & 4.0 & 1.5 & 5.5 & 5.45 \\
\hline Sector 21 & 0.75 & 3.0 & 1.5 & 4.5 & 6.67 \\
\hline Sector 22 & 0.75 & 3.0 & & 4.5 & 6.67 \\
\hline
\end{tabular}

\subsection{Accessibility Index \& PTALs}

The existing Accessibility Index of the selected POI has been calculated by adding the EDF of both DTC Buses and Metro Rail at the POI. The PTAL corresponding to the Accessibility Index Range at each
POI has been selected from Table 1 . The existing PTALs in Dwarka have been presented in the Table 5 and Fig. 2a. The existing PTALs of the study area sectors are in the range of $1 b$ and 2 which indicate $a$ poor level of accessibility in the area (refer Table 1).

\section{Table 5}

Existing PTALs in Dwarka

\begin{tabular}{|l|l|l|l|l|}
\hline Location (POI) & $\begin{array}{l}\text { EDF } \\
\text { Bus }\end{array}$ & $\begin{array}{l}\text { EDF } \\
\text { Metro }\end{array}$ & $\begin{array}{l}\text { Existing Accessibility } \\
\text { Index }\end{array}$ & Existing PTALs \\
\hline NSIT & 3.19 & 3.16 & 6.35 & 2 \\
\hline GGSIPU & 1.42 & 3.53 & 4.95 & $1 \mathrm{~b}$ \\
\hline Sector 3 & 5.88 & 2.61 & 8.49 & 2 \\
\hline Sector 4 & 3.09 & 2.61 & 5.70 & 2 \\
\hline Sector 5 & 2.02 & 2.40 & 4.42 & $1 \mathrm{~b}$ \\
\hline Sector 6 & 2.31 & 2.22 & 4.53 & $1 \mathrm{~b}$ \\
\hline Sector 7 & 2.13 & 3.16 & 5.28 & 2 \\
\hline Sector 8 & 2.12 & 4.62 & 6.73 & 2 \\
\hline Sector 9 & 2.25 & 4.00 & 6.25 & 2 \\
\hline Sector 10 & 2.32 & 6.67 & 8.99 & 2 \\
\hline Sector 11 & 2.13 & 5.45 & 7.58 & 2 \\
\hline Sector 12 & 3.02 & 5.45 & 8.47 & 2 \\
\hline Sector 13 & 3.81 & 5.45 & 9.26 & 2 \\
\hline Sector 14 & 2.49 & 5.45 & 7.94 & 2 \\
\hline Sector 21 & 3.02 & 6.67 & 9.68 & 2 \\
\hline Sector 22 & 2.13 & 6.67 & 8.79 & \\
\hline
\end{tabular}




\section{Improvement in Public Transport Accessibility Levels of the Study Area}

It is clear from the above analysis that the level of accessibility in Dwarka is very poor and needs significant improvement. PRT usually has close station spacing which increases the number of Service Access Points. Higher the number of PRT Stations, the lesser is the access time to the service. So, PRT can provide the last mile connectivity to the users with high level of accessibility. The Accessibility Indices and PTALs of the study area sectors have been calculated for the scenario when the proposed PRT will be running in Dwarka in the following sections.

\subsection{PRT Equivalent Doorstep Frequency (EDF)}

The PRT route and stations have been designed such that the distance between any POI and to the nearest PRT Station (SAP) would be less than or equal to 200 $\mathrm{m}$. Taking this distance and an average walk speed of $1.2 \mathrm{~m} / \mathrm{s}$, the access time to any SAP would be not more than 1.5 minutes. One of

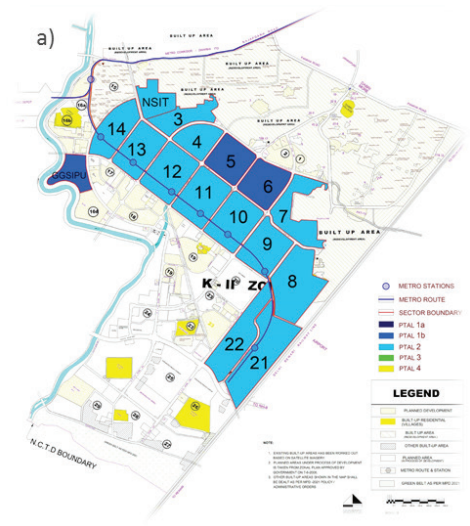

the characteristics of a PRT system is that the pod-cars are waiting for the passengers at the station. So as per the operational characteristic of the system, the waiting time would ideally be zero. An average waiting time of fifteen seconds has been taken as a factor of safety in case a pod car is making an empty run to the PRT station (Anderson, 2009). Using these values of waiting time and access time, the EDF of PRT will be 17.14 at every POI. The EDF is same at every POI because the maximum walk time to the SAP and the average waiting time at the SAP are both constant.

\subsection{Improved Accessibility Index \& PTALs}

The Accessibility Index of the selected POI for the scenario with PRT has been calculated by adding the EDF of DTC Buses, Metro Rail and PRT at every POI. The PTAL corresponding to the Accessibility Index Range at each POI has been selected from Table 1 . The existing and improved PTALs of Dwarka have been shown in the Table 6. The comparison of accessibility levels in the case study sectors have also been depicted spatially in Fig. 2 .

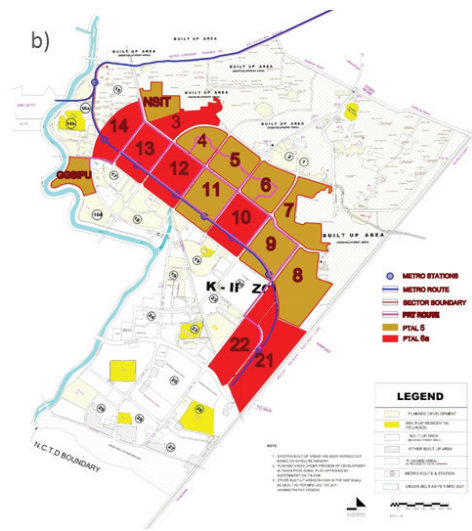

Fig. 2.

a) Existing PTALs in Dwarka (Before PRT)

b) Improved PTALs in Dwarka (After PRT) 
Table 6

Improved PTALs in Dwarka

\begin{tabular}{|c|c|c|c|c|c|c|c|c|c|}
\hline $\begin{array}{l}\text { Location } \\
\text { (POI) }\end{array}$ & $\begin{array}{l}\text { EDF } \\
\text { Bus }\end{array}$ & $\begin{array}{l}\text { EDF } \\
\text { Metro }\end{array}$ & $\begin{array}{l}\text { EDF } \\
\text { PRT }\end{array}$ & $\begin{array}{l}\text { Accessibility Index } \\
\text { Before PRT }\end{array}$ & $\begin{array}{l}\text { PT } \\
\text { Be }\end{array}$ & $\begin{array}{l}\text { ALs } \\
\text { ore PRT }\end{array}$ & $\begin{array}{l}\text { Accessibility Index } \\
\text { After PRT }\end{array}$ & PTA & $\begin{array}{l}\text { Ls } \\
\text { PRT }\end{array}$ \\
\hline NSIT & 3.19 & 3.16 & 17.14 & 6.35 & 2 & Poor & 23.49 & 5 & Very Good \\
\hline GGSIPU & 1.42 & 3.53 & 17.14 & 4.95 & 16 & Very Poor & 22.09 & 5 & Very Good \\
\hline Sector 3 & 5.88 & 2.61 & 17.14 & 8.49 & 2 & Poor & 25.63 & $6 a$ & Excellent \\
\hline Sector 4 & 3.09 & 2.61 & 17.14 & 5.70 & 2 & Poor & 22.85 & 5 & Very Good \\
\hline Sector 5 & 2.02 & 2.40 & 17.14 & 4.42 & $1 b$ & Very Poor & 21.56 & 5 & Very Good \\
\hline Sector 6 & 2.31 & 2.22 & 17.14 & 4.53 & $1 b$ & Very Poor & 21.68 & 5 & Very Good \\
\hline Sector 7 & 2.13 & 3.16 & 17.14 & 5.28 & 2 & Poor & 22.43 & 5 & Very Good \\
\hline Sector 8 & 2.12 & 4.62 & 17.14 & 6.73 & 2 & Poor & 23.88 & 5 & Very Good \\
\hline Sector 9 & 2.25 & 4.00 & 17.14 & 6.25 & 2 & Poor & 23.39 & 5 & Very Good \\
\hline Sector 10 & 2.32 & 6.67 & 17.14 & 8.99 & 2 & Poor & 26.13 & $6 a$ & Excellent \\
\hline Sector 11 & 2.13 & 5.45 & 17.14 & 7.58 & 2 & Poor & 24.72 & 5 & Very Good \\
\hline Sector 12 & 3.02 & 5.45 & 17.14 & 8.47 & 2 & Poor & 25.61 & $6 a$ & Excellent \\
\hline Sector 13 & 3.81 & 5.45 & 17.14 & 9.26 & 2 & Poor & 26.40 & $6 a$ & Excellent \\
\hline Sector 14 & 2.49 & 5.45 & 17.14 & 7.94 & 2 & Poor & 25.09 & $6 a$ & Excellent \\
\hline Sector 21 & 3.02 & 6.67 & 17.14 & 9.68 & 2 & Poor & 26.83 & $6 a$ & Excellent \\
\hline Sector 22 & 2.13 & 6.67 & 17.14 & 8.79 & 2 & Poor & 25.94 & $6 a$ & Excellent \\
\hline
\end{tabular}

\section{Conclusions}

Personal Rapid Transit is one of the emerging transportation modes and has the potential to provide the last mile connectivity to the users. Introducing a PRT system in an area ensures high levels of accessibility in the area. With the increase in the accessibility levels, a higher usage of public transport and reduction in private modes of transportation can be expected. The case study sectors of Dwarka are served by the Delhi Transport Corporation Buses and Delhi Metro Rail at present. Still the PTALs of study area sectors fall in the range of $1 \mathrm{~b}$ and 2 which indicate a poor level of accessibility. After the introduction of PRT in Dwarka, significant improvement can be observed in the accessibility levels of the sectors. The PTALs of the study area sectors shoot up to 5 and 6 a which indicates excellent levels of accessibility. Thus PRT can be used as a feeder system to the existing public transport systems to provide the last mile connectivity to the users. A multimodal seamless integration of PRT with other public transport modes like MRTS and buses has the potential to meet the urban transport deficit and increase the share of public transport users in the area. The implementation of PRT as a standalone network to serve the transportation needs of an urban area is yet to be explored.

\section{References}

Anderson, J.E. 1978. What is Personal Rapid Transit. University of Washington, USA.

Anderson, J.E. 1996. Some Lessons from the History of Personal Rapid Transit. In Proceedings of the Conference on PRT and Other Emerging Transit Systems. Minneapolis, USA.

Anderson, J.E. 2009. An Intelligent Transportation Network System: Rationale, Attributes, Status, Economics, Benefits, and Courses of Study for Engineers and Planners. PRT International, LLC. 
ATA. 2016. PRT is not a novel concept: History of PRT. Advanced Transit Association. Available from Internet: $<$ http://www.advancedtransit.org/advanced-transit/ history/>.

Balya, M.I.; Katti, B.K.; Saw, K. 2016. Spatial transit accessibility modeling of Indian metropolitan city in GIS environment, International Journal for Traffic and Transport Engineering, 6(1): 51-62.

De Graff, M. 2011. PRT Vehicle Architecture and Control in Masdar City. In Proceedings of the 13th International Conference on Automated People Movers and Transit Systems, 339-348.

European Commission. 2004. Fifth Framework Programme Key Action-City of Tomorrow and Cultural Heritage. EDICT Final Report.

Gilbert, R.; Anthony, P. 2006. Grid-connected vehicles as the core of future land based transport systems, Energy Policy, 35(5): 3053-3060.

Gustafsson, J.; Lohmann, R.; Lowson, M. 2013. Personal Rapid Transit Live Applications Challenges. In Proceedings of the Third International Conference on Urban Public Transportation Systems, 347-356.

Jain, U.; Sarkar, P.; Vibhuti, A.; Arora, D. 2016. Demand estimation of Personal Rapid Transit (PRT) using stated preference technique and binary logit models, Journal of Transport Literature, 10(2): 5-9.

Kumar, M.; Sarkar, P.K.; Madhu, E. 2013. Development of fuzzy logic based mode choice model considering various public transport policy options, International Journal for Traffic and Transport Engineering, 3(4): 408-425.

London Datastore. 2014. Transport for London - Measuring public transport accessibility levels. Greater London Authority. Available from Internet: $<$ http://data.london.gov.uk/dataset/public-transportaccessibility-levels/resource/86bbffe1-8af1-49ba-ac9bb3eacaf68137>.
Moeinaddini, M.; Shekari, Z.A.; Shah, M.Z. 2012. The effectiveness of private motorized trips indicators in reducing car usage, International Journal for Traffic and Transport Engineering, 2(4): 347-358.

Muller, P.J. 2009. The Impact of PRT on Army Base Sustainability. Automated People Movers. 309-320.

Sarkar, P.K.; Maitri, V.; Ram, S.; Meenaz, I. 2012. Personalized Rapid Transit Systems - An Approach towards Solving Urban Transport Problems, A Case Study in Gurgaon City, Haryana. School of Planning \& Architecture, New Delhi, India.

Šimecki, A.; Steiner, S.; Čokorilo, O. 2013. The accessibility assessment of regional transport network in the south east Europe, International Journal for Traffic and Transport Engineering, 3(4): 351-364.

Ultra Fairwood. 2009. DPR of PRT Amritsar Project. Detailed project Report, Ultra Fairwood Pvt. Ltd., India.

Ultra Global. 2014. World's first and largest urban PRT system announced. Available from Internet: <http:// www.ultraglobalprt.com/worlds-largest-urban-prtsystem-announced $>$.

Ultra Global. 2013. Heathrow announces plans for an additional Personal Rapid Transit (PRT) system. Available from Internet: <http://www.ultraglobalprt. com/heathrow-announces-plans-additional-personalrapid-transit-prt-system-heathrow $>$.

Vibhuti, A. 2009. Personal Rapid Transit: A Suitable Mass Transit Alternative for India, Journal of Institute of Urban Transport, 6(2): 7-12.

\section{jitte 324}

